\title{
A História na Literatura: princípios de abordagem.
}

Maria Teresa de Freitas

Departamento de Letras Modernas - FFLCH/USP

Literatos e historiadores mantêm relações que se assemelham às dos velhos casais: vivem juntos há longo tempo, mantêm laços ao mesmo tempo cúmplices e conflitantes, juram acabar com tudo definitivamente durante as muitas cenas conjugais, e no fim, acabam ligados "na dor e na alegria" por uma conivência profunda. Esse "casamento", aliás, não é recente; foi celebrado, pode-se dizer, por volta de 1864, e o "Juiz de Paz" chamava-se Hippolyte Taine.

$\mathrm{Na}$ época, a História era considerada como a Ciência-modelo, a Ciência das Ciências; estudar uma atividade humana, significava antes de mais nada, estabelecer suas origens, reconstituir sua gênese. Determinados os fatores que constituíam os "causas primeiras" dos fatos, seguia-se então o desenrolar da "causalidade", explicando-se tudo - ou quase tudo por esse encadeamento das causas às suas consequiências; assim, parecia-se estar cada vez mais apto a estabelecer tudo aquilo que determina um fato. Taine tentou aplicar esse esquema à literatura; para ele, o escritor era movido por três forças principais, que ele denominava "facultés maîtresses": a raça (disposiçōes hereditárias), o meio (clima, solo, circunstâncias políticas duráveis, condiçōes sociais permanentes) e o momento (a época em que se modificam essas forças iniciais). $\mathrm{O}$ mecanismo do texto repousava sobre esses três dados, e, a partir deles, uma obra poderia ser inteiramente explicada.

Essa teoria ambiciosa, que Taine defendeu com grande poder de síntese, fundamenta-se em três postulados: em primeiro lugar, o postulado de toda ideologia universitária positivista da segunda metade do século XIX e início do século XX: o pesquisador deve estabelecer fatos bem circunscritos, e, na medida do possível, irrefutáveis; o que conta, não é o sentido de uma obra, mas as condições de sua produção; o texto literário se reduz a um resultado, é um produto. Segundo postulado - que 
decorre do primeiro: não se deve "simpatizar" com uma obra literária, seria anti-científico tentar compreendê-la por dentro: ela deve ser examinada o mais friamente possível, para poder ser explicada. Terceiro postulado: os textos literários não interessam por si mesmos, mas como documentos sobre a psicologia de um povo, sobre o estado de espírito de uma sociedade, ou sobre a situação histórica de uma época; apreciá-los pelo simples "plaisir du texte" - como dirá mais tarde Roland Barthes - equivaleria a desviar o espírito crítico de seu verdadeiro objetivo.

Gustave Lanson, 1903, proporá um programa de trabalho para constituir aquilo que seria, para ele, uma "história literária da França", ou seja, "um quadro da vida literária da nação, a história da cultura e da atividade da multidão desconhecida que lia, bem como dos escritores que escreviam (1); trata-se pois de uma história das circunstâncias, das condições e das repercussões sociais do fato literário. Em 1941, o historiador Lucien Febvre precisava o que poderia ser uma história literária assim concebida - "a história de uma literatura numa determinada época, nas suas relações com a vida social dessa época. Seria preciso pôr em relação as mudanças de hábito, de gosto, de forma de escrever e de preocupação dos escritores com as vicissitudes da política, com as transformações da mentalidade religiosa, com as evoluções da vida social, com as mudanças da moda artística e dos gostos, etc." (2).

Esse projeto não deixa de ser interessante. Mas ele faz da história literária um caso particular da história geral da sociedade, de suas representações, daquilo que L. Febvre chamava de "outillage mental". Os textos literários fornecem material, da mesma forma que as correspondências, os testamentos ou os registros de cartório, sobre uma sociedade ou uma época, mas eles não têm caráter específico. Onde está a diferença entre um texto literário e uma página qualquer, escrita na mesma época? Não haveria, num texto literário, uma intenção particular, um projeto diverso, um "excedente" de sentido?

Na verdade, o projeto de Lanson não foi levado em frente. Seus sucessores se contentaram - embora escrupulosamente - em estabelecer as origens de um texto, em descobrir as influências que se exerceram sobre o escritor, em relacionar sua obra com sua biografia, em inseri-lo na história dos gêneros, das escolas ou das gerações. Esse trabalho é necessário para "limpar o terreno" e evitar contra-sensos e anacronismos; é um trabalho preparatório, que não é suficiente para dar conta do efeito que produz um texto. Acima de tudo, uma obra não se reduz àquilo que a condiciona: ela se inscreve, é claro, num meio e num contexto; mas esse meio, ela o

(1) - Essais de méthode, de critique et d'histoire littéraire. Paris, Hachette, 1965.

(2) - Combats pour l'Histoire. Paris , Colin, 1943. 
preenche à sua maneira; esse contexto, ela o elabora segundo modalidades que lhe são próprias.

$\mathrm{Na}$ década de 1960, a crítica textualista e estrutural fez com que as atenções se concentrassem exclusivamente no próprio texto, no seu funcionamento interno. Assim como a música não representa o despertar da primavera, mas é constituída por uma determinada disposição de sons; assim como a pintura não representa uma batalha naval ou uma paisagem, mas é formada por uma certa relação de cores e de formas numa tela; assim também o texto literário se reduz a uma estrutura formal a uma determinada elaboração da linguagem. E indiferente que sua matéria seja uma situação histórica ou social ou estados de espírito: o texto remete apenas a si mesmo, é fechado. Esse tino de abordagem repousa também sobre postulados: em primeiro lugar, uma nova ciência-modelo, uma nova Ciência das Ciências, destronou a História: a Linguística ou, mais em geral, as Ciências da Informação e da Comunicação; em seguida, como para Taine e Lanson, não se trata de apreender o sentido dos textos, mas de pôr em evidência seu funcionamento; e finalmente, embora os críticos textualistas já não pensem mais em termos de gênese ou processo, eles reduzem a obra ao funcionamento de um código. Trata-se na verdade de uma nova forma de positivismo: enquanto Taine ou Lanson se perguntavam de onde vem a obra literária, a crítica textualista se pergunta como ela funciona. Nos dois casos evita-se colocar outras questōes certamente mais importantes: o que a obra implica? Para onde ela se dirige? Qual é a dinâmica que a anima e que sustenta? Para simplificar: em que determinada obra nos diz respeito? Há já alguns anos os problemas das relações entre Literatura e História começaram a ser colocados em outros termos. A História Literária não se apresenta mais como simples disciplina anexa à História, os literatos não estão mais "no rastro" dos historiadores mas tampouco a Literatura é considerada como um discurso fechado; um romance não é encarado mais como um simples reflexo, emanação ou produto das circunstâncias históricas, mas tampouco ele se reduz a um sistema de formas sem relação com o movimento histórico e social. A criação artística exerce uma função social, mas é ao mesmo tempo, um processo singular; ela tem modos de comunicação particulares que podem ser colocados em relação com outras linguagens, desde que seja a partir de paralelismos não arbitrários e fundados sobre outras bases que não a simples analogia. A grande questão é: como estabelecer de maneira rigorosa tais paralelismos?

A arte não representa o universo, mas ilustra os valores de uma cultura. Em outras palavras, ela não fornece a confirmação de um saber que se poderia adquirir de outras formas, por uma enquete sociológica ou uma pesquisa histórica tradicional, por exemplo; ela tem princípios e leis diferentes dos da realidade exterior já inventoriada. O artista, quando não é acadêmico, ultrapassa incessantemente os sistemas de classificação aos quais 
uma sociedade confina suas representações provisórias do mundo. A arte é uma modalidade do imaginário, e este não reproduz a realidade exterior, mas a transforma, exprimindo o que nela está reprimido ou latente.

E necessário também não esquecer que Literatura e História não evoluem obrigatoriamente na mesma cadência; há que se levar em conta as diferenças de ritmo das duas séries. Às vezes os escritores ficam marcados por representações e ideologias anteriores àquelas que predominam em sua época; em outros casos, os textos se antecipam aos acontecimentos, constituindo então uma forma de comunicação social que ainda não encontrou seu contexto. Examinemos cada um desses casos.

Primeira hipótese: algumas representações do mundo sobrevivem, na memória e no imaginário, às situações históricas e sociais nas quais foram criadas. Marx já se perguntara: como é possível que a arte grega nos envolva ainda, se nós não vivemos mais num modo de produção escravocrata? Ora, a resposta parece estar justamente no fato de que as representações evoluem em ritmo diferente das condições exteriores objetivas; na época atual, por exemplo, a terra se encontra praticamente toda explorada e cartografada, e nós ainda ficamos fascinados diante de romances como os de Gracy (Le Rivage des Syrtes, entre outros) ou os de Buzzati ( $O$ Deserto dos Tártaros, por exemplo), que nos levam às portas de terras desconhecidas. Se aprofundarmos um pouco a análise, constataremos que, numa determinada formação social, coexistem diferentes modos de produção, uns dominantes, outros ultrapassados - ou em vias de sê-lo; alguns rurais, alguns moradores de cidades pequenas, vivem ainda numa esfera de trabalho e de relação sociais que pouco diferem da época anterior ao capitalismo. Além disso, certas formações sociais podem desaparecer sem ter levado a termo suas possibilidades, e a literatura pode exprimir um passado mal acabado, reprimido, e prolongar suas virtualidades. A História dos acontecimentos não esgota a História: além dela, e incidindo num espaço temporal mais longo, temos a História estrutural - a das instituições, dos costumes, dos modos de produção - e, numa duração ainda mais longa, aquela que F. Braudel chama de História imóvel (3), das mentalidades, e dos "excluídos da História", aqueles que não estão nem no poder nem em papéis de destaque: é a essa História que a Literatura remete, quando exprime as nostalgias, as angústias, as carências, as mágoas e as aspirações daqueles que sentiram a História escapar de suas mãos ou que nem ao menos chegaram, um dia, a ocupar nela um lugar qualquer. A criação literária que tenta recuperar valores ultrapassados, ou que simplesmente se volta para formações sociais do passado, pode representar uma

(3) - "Histoire et Sciences Sociales: la longue durée", in Annales, oct. 1958, págs. 725-753. 
reação positiva contra o caráter desumano de um mundo reduzido à racionalidade instrumental.

Segunda hipótese: a Literatura prenuncia os acontecimentos. Essa fórmula não teria muito sentido se ela pretendesse atribuir aos escritores dons de videntes hiper-lúcidos, de profetas visionários dos fatos históricos futuros. Entretanto, não se pode deixar de constatar que, em certos períodos politicamente estáveis e economicamente prósperos, alguns escritores pressentem a existência de agitações subjacentes; é assim que, em 1928, um ano antes do estouro da grande crise de 1929 que praticamente nenhum expert previa, aparecia simultaneamente na França Les dernières nuits de Paris de Philippe Soupault, Blèdre de Drieu la Rochelle, La voie royale de Malraux e sobretudo Nadja de André Breton, romances que, sob pontos de vista diferentes, repetem a mensagem de rádio captada bruscamente no final de Nadja: "Há alguma coisa errada". Perturbações no inconsciente e no imaginário anunciam desequilíbrios sociais; alguns textos literários captam, no inconsciente coletivo, movimentos ainda embrionários, e exprimem indiretamente, através de imagens, mudanças já iniciadas nas profundezas mas que ainda não chegaram à superfície. Em alguns casos, é fato, tais tendências podem não se confirmar: os romances da década de 50 por exemplo, mostram-se, em sua maioria, obcecados pela idéia de uma terceira guerra mundial; casos como esse servem de advertência contra a possível confusão entre Literatura e prospectiva: como bem lembrou M. de Certeau, uma sociedade exprime freqüentemente aquilo que ela está construindo pelas representações daquilo que ela está perdendo (4). Não devemos portanto nos iludir sobre a clarividência excepcional dos escritores, mas apenas considerar algumas de suas obras como registradoras de temores difusos, de inquietações desarrazoadas, de desejos e aspirações ainda não formulados de um grupo social; expressão do conteúdo latente de uma época. E mais: dificilmente um escritor conseguiria transcrever perfeitamente esse conteúdo latente; ele só poderá fazê-lo através de aproximações e de figuras, mas que permitem ao menos detectar os sintomas de uma perturbação coletiva subjacente, esse fundo histórico secreto que desaparece por trás da trama dos acontecimentos (5).

Essas considerações levam-nos a entrever a zona de fertilidade que existe no cruzamento da Literatura com a História: as obras literárias que melhor traduzem os movimentos sociais e históricos não são as que retratam de forma escrupulosamente exata os acontecimentos exteriores; são as que exprimem aquilo que falta a um grupo social, e não aquilo que ele possui plenamente. $O$ escritor vai dar uma forma às aspirações ainda inconscientes desse grupo; não que ele saiba mais do que os outros; ele também se

(4) - L'Ecriture de l'Histoire. Paris, Gallimard, 1975.

(5) - A Expressão é de A. Breton, em La Clé des Champs, Paris, Pauvert, 1967. 
perde em toda espécie de contradição: entre temores e esperanças, entre ideologias passadas e ideologias novas, entre representações inéditas e formas ultrapassadas ou vice-versa, entre os sistemas de representação de diferentes meios ou de diferentes grupos aos quais ele pertence simultaneamente, etc. Mas essas contradições, o texto literário as mostra; a obra literária "eficaz", que age sobre seus leitores, é aquela que dramatiza as contradições, exacerba-as, leva-as às últimas consequiências - ou seja, representa-as -, e oferece assim um princípio de resposta a perguntas ainda não claramente formuladas. Ao experimentar novas formas de relações dos homens ou outros homens e com seu meio ambiente, a obra literária libera possibilidades subjacentes a certas situações, joga com esas possibilidades, dá-lhes vida e faz com que elas, sob forma imaginária, comecem a se realizar; ela tenta assim explorar as virtudes inerentes a uma época.

Estudar as relações da Literatura com a História não significa portanto buscar naquela o reflexo desta; mais do que a imagem, a Literatura seria antes o imaginário da História; ou, para utilizar a vigorosa expressão de Malraux, o "canto da História", a música que dela emana.

Um canto, uma música: formas. O movimento histórico e social se inscreve em formas: momentaneamente, um processo em evolução se fixa e se cristaliza. A forma é a mediação concreta entre a estrutura das obras literárias e a de uma formação social; é necessário entretanto que não se entenda "forma" numa acepção estática, no sentido em que falamos da forma de um vaso ou do contorno de uma estátua. A História é movimento e mutação: tentar petrificá-la seria um contra-senso; a forma de uma obra é o movimento que a anima, a dinâmica que a impulsiona. Esse movimento, em algumas obras, confunde-se com as tendências do desenvolvimento histórico; em outras, ele está em sentido contrário. Em certos casos, as aspirações são realizáveis; em outros, ela se chocam contra a resistência das instituições, contra a força da ordem das coisas, e sua trajetória é forçosamente desviada. De qualquer forma, é necessário confrontar o movimento de uma formação social com o de uma obra; assim como na História se dilaceram povos e classes, na obra se dilaceram linguagens.

Literatura e História não são portanto independentes uma da outra, mas tampouco estão ligadas entre si por relações mecânicas de causa e efeito; a História é imanente às obras, e não uma fatalidade exterior a elas; ela é parte integrante de sua dinâmica interna e ao mesmo tempo, se elabora através delas. Presença da História nas obras, e não influência da História sobre as obras: é o que deverá guiar a análise que se pretende produtiva das relações entre Literatura e História. 